\title{
Research on Control Strategy of Super Capacitor Energy Storage System in Traction Elevator
}

\author{
Qian Xun \\ School of Engineering \\ Huzhou University \\ Huzhou, Zhejiang, P.R. China \\ xunq520@hotmail.com \\ Lidi Quan \\ School of Engineering \\ Huzhou University \\ Huzhou, Zhejiang, P.R. China \\ quanlidi@hutc.zj.cn
}

\author{
Peiliang Wang \\ School of Engineering \\ Huzhou University \\ Huzhou, Zhejiang, P.R. China \\ wpl@hutc.zj.cn \\ Yuxiang $\mathrm{Xu}$ \\ School of Engineering \\ Huzhou University \\ Huzhou, Zhejiang, P.R. China \\ xyx2008@hutc.zj.cn
}

\begin{abstract}
To improve the overall efficiency of modern building elevator, an active regenerative braking converter using a bidirectional Buck-Boost converter is implemented. The converter is connected in parallel to the inverter DC-bus. Energy is stored in a set of super capacitors during regeneration and it is transferred back to the DC-bus when the elevator accelerates. The control strategy of the storage system with super capacitors is proposed. In order to validate the effectiveness of the proposed method, the simulation model of the elevator system has been built up. Simulation results show that the control strategy can achieve recycling and reuse of regenerative energy in traction elevator.
\end{abstract}

Keywords-Efficiency; Bukc-Boost; super capacitors; control strategy

\section{INTRODUCTION}

With the rapid growth of China's economic strength, the contradiction between power supply and demand is becoming increasingly prominent, and the shortage of electric energy restricts the development of national economy, energy conservation and emission reduction has become an important part of national strategy [1]. In China, about $30 \%$ of the social energy consumption is the building energy consumption, which is the largest energy consumption. Therefore, the reduction of energy consumption has become a key factor for the competitiveness of elevators as it can essentially improve the total efficiency of a building [2].

energy

When the elevator operates in descending with heavy load and upward with light load or braking state, regenerative energy is generated, transported to the super capacitor paralleled to the inverter DC side by the freewheeling diode,

This work was supported by the Province Public Welfare Technology Research Industry Project for Zhejiang under grand No. 2016C31115 and Huzhou public welfare Technology Application Research Project under grant No. 2015 GZ05. which produces pumping voltage in the DC side [3]. In order to restrain the pumping voltage, the energy consumption resister is usually used, it is easy to implement, but the regenerative energy is wasted in the form of heat, which causes high temperature in the engine room, and the heat dissipation cost is increased. With the development of grid connected technique, the regenerative energy feedback to power grid [4-5] to achieve energy saving and green environmental protection, which can reduce the energy consumption, while it faces similar technical problems to wind, solar and other grid-connected equipment, and the power of elevator in different operation conditions changes a lot, in the energy feedback process the power grid voltage is influenced, affecting its normal operation. The downstream of the grid users will be disturbed, and even the safe operation of power grid is affected, so additional strategy has to be used to have better power quality.

With the development of new energy storage technology such as flywheel, superconductor, super capacitor, energy feedback technology based on energy storage device with super capacitor is widely used in the control of elevator energy saving [6-14]. Aiming at the shortcoming of fluctuation regenerative energy affects the power quality in energy feedback power grid, [6] proposes grid power optimization control to reduce the fluctuation of power grid and improve the power quality. The method of traffic flow difference was introduced in [7] to determine the capacity of the super capacitor in elevator energy storage, and the control strategy under different energy state is studied. The structure and control strategy of super capacitor energy storage for elevator is analyzed in [8-11]. For imbalanced voltage of single capacitor, super capacitor voltage balancing strategy is proposed in [12] to prevent the voltage unbalance of influence system safety. In [13-14], energy management of super capacitor energy storage system is studied. 
In view of the traction elevator energy saving control, the paper presents a control strategy for energy storage elevator based on bidirectional Buck-Boost converter. Firstly, the structure of the energy storage elevator is introduced. And then, the equivalent circuit and mathematical model of storage energy system are analyzed, on this basis, the charging and discharging of super capacitor control strategy is studied. Finally, the simulation model of the elevator system is built up.

\section{StRUCTURE OF ENERGY SOTRAGE ELEVATOR WITH SUPER CAPACITOR}

Figure 1 shows the energy storage elevator with super capacitor, which is mainly composed of AC power source, bridge rectifier, inverter, traction machine, weight, car and super capacitor unit.

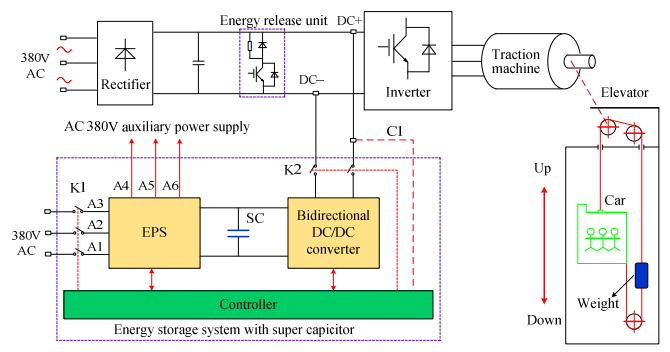

Fig.1 Energy saving elevator with super capacitor

When the elevator operates in descending with heavy load, upward with light load or deceleration and braking state, traction machine is in renewable power state, regenerative energy is inverted into DC power, and then stored in the super capacitor unit through bidirectional converter. On the one hand, the stored energy can be transformed back to the DCbus to provide energy of the traction machine by the bidirectional converter when the elevator operates in motor state again, on the other hand, it can provide energy to elevator auxiliary system by the emergency power supply. Generally, multiple super capacitor series was connected in parallel or series to form a super capacitor unit.

DC/DC bidirectional converter, super capacitor unit (SC) and emergency power supply (EPS) together constitute the super capacitor energy systems, cooperated with the inverter to improve the overall efficiency of the elevator.

\section{Model of Energy Storage System With Super CAPACITOR}

\section{A. Equivalent circut}

$\mathrm{DC} / \mathrm{DC}$ bidirectional converter is the core component to realize energy recovery and reuse, one end is connected to the inverter DC-bus and the other end is connected with the super capacitor unit. The super capacitor unit is connected in parallel or series with a lot of super capacitors according to the capacity requirement, and the physical characteristic is complex. In order to facilitate the analysis of the power converter, the lumped circuit model of the super capacitor is adopted. Therefore, the equivalent circuit model of the energy storage system with super capacitor can be established as shown in Figure 2, in which, $R_{\mathrm{es}}$ is equivalent series resistance, $R_{\mathrm{ep}}$ is the equivalent parallel resistance, $C_{\mathrm{SC}}$ is the ideal capacitor, $i_{\mathrm{SC}}$ is the charging and discharging current of the super capacitor, $v_{\mathrm{SC}}$ is the voltage of super capacitor.

When $\mathrm{VT}_{1}$ is on, $\mathrm{VT}_{2}$ is periodic turn on and turn off, bidirectional DC/DC converter works as a boost converter, the super capacitor is in the discharging state, for a switch period $T$, assuming the turn on time of $\mathrm{VT}_{2}$ is $t_{\text {on }}$, and the turn off time is $t_{\text {off }}$, on the basis of energy conservation, it can be obtained that

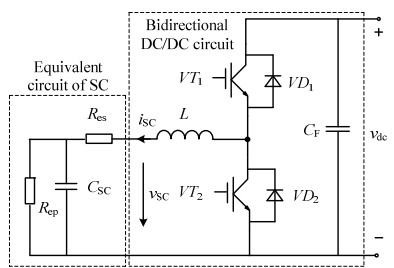

Fig.2 Equivalent circuit of energy storage system with super capacitor

$$
v_{d c}=\frac{t_{\text {on }}+t_{\text {off }}}{t_{\text {off }}} v_{s c}=\frac{T}{t_{\text {off }}} v_{s c}
$$

When $\mathrm{VT}_{2}$ is off, $\mathrm{VT}_{1}$ is periodic turn on and turn off, bidirectional DC/DC converter works as a buck converter, the super capacitor is in the charging state, for a switch period $T$, assuming the turn on time of $\mathrm{VT}_{1}$ is $t_{o n}$, and the turn off time is $t_{\mathrm{off}}$, on the basis of energy conservation, it can be obtained that

$$
v_{s c}=\frac{t_{o n}}{t_{o n}+t_{o f f}} v_{d c}=\frac{t_{o n}}{T} v_{d c}
$$

\section{B. Mathmatical model of the converter}

\section{1) Buck working mode}

When the elevator operates in renewable power generation, and the capacitor voltage does not reach the maximum threshold voltage, regenerative energy generated by traction machine will be stored in super capacitor unit through bidirectional DC/DC converter, converter works in buck mode, the small signal mathematical model is shown in Figure 3.

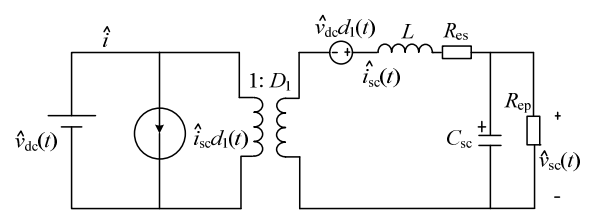

Fig.3 Small signal mathematical model of Buck

Set the small signal disturbance of DC bus voltage $\hat{v}_{d c}=0$, the transfer function from the duty cycle to the current disturbance, and the current disturbance to the voltage disturbance of the super capacitor can be got

$$
\begin{gathered}
G_{b u c k i d}=\frac{\hat{i}_{s c}(s)}{\hat{d}_{1}(s)}=\frac{\left(R_{e p} C_{s c} s+1\right) v_{d c}}{R_{e p} C_{s c} s^{2}+\left(L+R_{e s} R_{e p} L C_{s c}\right) s+R_{e s}+R_{e p}} \\
G_{b u c k v i}=\frac{\hat{v}_{s c}(s)}{\hat{i}_{s c}(s)}=\frac{R_{e p}}{R_{e p} C_{s c} s+1}
\end{gathered}
$$

The voltage and current double closed loop control is composed by the voltage $v_{\mathrm{SC}}$ and the charging current $i_{\mathrm{SC}}$ of the super capacitor, the control block diagram of which is shown in Figure 4. 


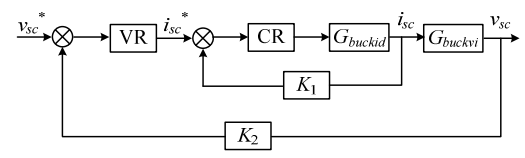

Fig.4 Control block diagram of Buck mode

\section{2) Boost working mode}

When the elevator operates in motor state, and the voltage of the capacitor is greater than the minimum threshold voltage, the super capacitor discharges first to supply energy to traction machine, converter works in boost mode, the small signal mathematical model is shown in Figure 5.

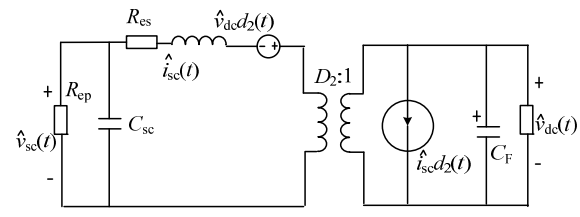

Fig.5 Small signal mathematical model of Boost

The transfer function from the duty cycle disturbance to the current disturbance and the current disturbance to the DC bus voltage disturbance can be derived

$$
\begin{gathered}
G_{\text {boostid }}=\frac{\hat{i}_{s c}(s)}{\hat{d}_{2}(s)}=\frac{\left(R_{e p} C_{F} s+2\right) v_{s c}}{\left(L C_{F} s^{2}+\left(\frac{L}{R}+R_{e s} C_{F}\right) s+\frac{R_{e s}}{R}+D_{2}^{2}\right) D_{2} R} \\
G_{\text {boostvi }}=\frac{\hat{v}_{d c}(s)}{\hat{i}_{s c}(s)}=\frac{D_{2}^{2} R-\left(L s+R_{e s}\right)}{\left(R C_{F} s+2\right) D_{2}}
\end{gathered}
$$

The DC bus voltage $v_{\mathrm{DC}}$ and discharging current $i_{\mathrm{SC}}$ are used to form the voltage and current double closed loop control, and the control block diagram of which is shown in Figure 6.

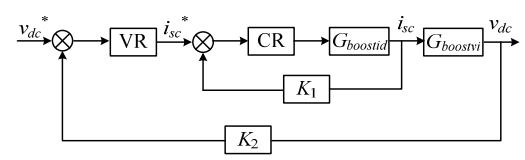

Fig.6 Control block diagram of Boost mode

\section{The Charging and Discharging Control Strategy OF SUPER CAPACITOR}

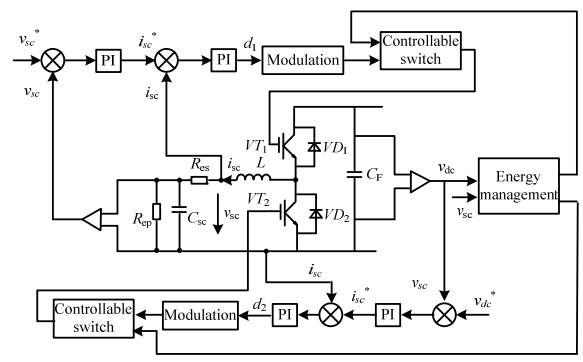

Fig.7 Control block diagram of super capacitor charging and discharging

The charging and discharging control of the super capacitor is completed by the different operation modes of the bi-directional DC/DC converter. When the super capacitor discharges, the bidirectional converter works in the buck mode; and when the super capacitor charges, the bidirectional converter works in the boost mode. It can be seen from Figure 4 , Figure 6 , the super capacitor voltage $v_{\mathrm{SC}}$, DC bus voltage $v_{\mathrm{DC}}$, super capacitor charging and discharging current $i_{\mathrm{SC}}$ are used as the control variables to get super capacitor charging and discharging control block diagram, which is shown in Figure 7.

The bidirectional converter works in buck mode or boost mode according to the DC bus voltage, super capacitor voltage and energy management strategy, and then the current reference can be determined, through the current regulator, and triangular wave cut production is accounted for duty cycle signal, Figure 8 shows the control block diagram of working mode switching.

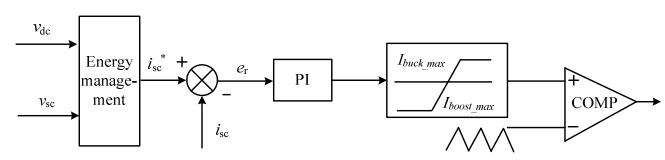

Fig. 8 Working mode switching

\section{Simulation}

To verify the effectiveness of the control strategy of the super capacitor energy storage system, the simulation model was built up in Matlab 2013/Simulink, and simulation parameters are shown in Table 1 below.

\section{TABLE I. The PARAmeters of the ENERGy Storage SyStem}

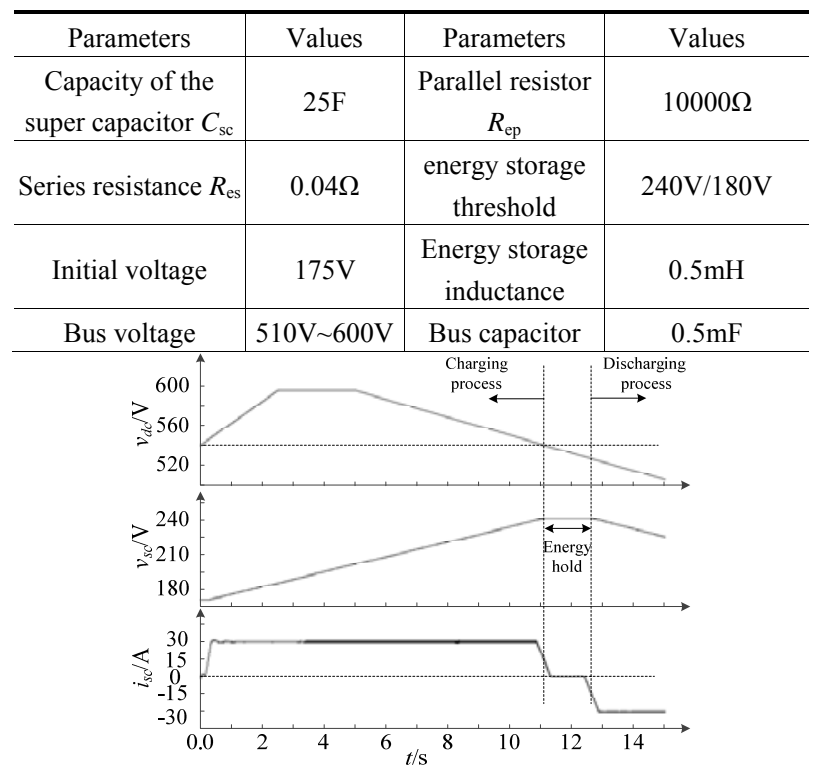

Fig.9 The braking process of traction elevator

Firstly, it gives the simulation of elevator braking process, when the DC bus voltage by $535 \mathrm{~V}$ increases up to $600 \mathrm{~V}$, several seconds later, and in the $600 \mathrm{~V}$ gradually reduced to $510 \mathrm{~V}$, the voltage and the current of the super capacitor in the process are shown in Figure 9. Thus, bidirectional converter operates in buck mode to charge the super capacitor, the voltage from the initial voltage $175 \mathrm{~V}$ rose to maximum voltage $240 \mathrm{~V}$, and maintain $240 \mathrm{~V}$ remains unchanged, the energy storage of the elevator is stored, when the DC bus voltage continued reducing in after, bidirectional converter operates in boost mode to discharge the super capacitor, the voltage began to decrease from $240 \mathrm{~V}$, the capacitive current is converted from positive to negative. 
During the charging and discharging process of the super capacitor, the simulation results of the voltage close to the threshold voltage are shown in Figure 10 and Figure 11. When the super capacitor charges, $v_{\mathrm{SC}}$ is gradually increased, as close to the maximum threshold voltage value, charging current $i_{\mathrm{SC}}$ decreases gradually, until $v_{\mathrm{SC}}$ increases to $240 \mathrm{~V}, i_{\mathrm{SC}}$ reduces to $0, \mathrm{VT}_{1}$ and $\mathrm{VT}_{2}$ are off. When the super capacitor discharges, $v_{\mathrm{SC}}$ is gradually decreased, as close to the minimum threshold voltage, discharging current $i_{\mathrm{SC}}$ decreases gradually, until the $v_{\mathrm{SC}}$ is down to $180 \mathrm{~V}, i_{\mathrm{SC}}$ reduces to $0, \mathrm{VT}_{1}$ and $\mathrm{VT}_{2}$ are off.
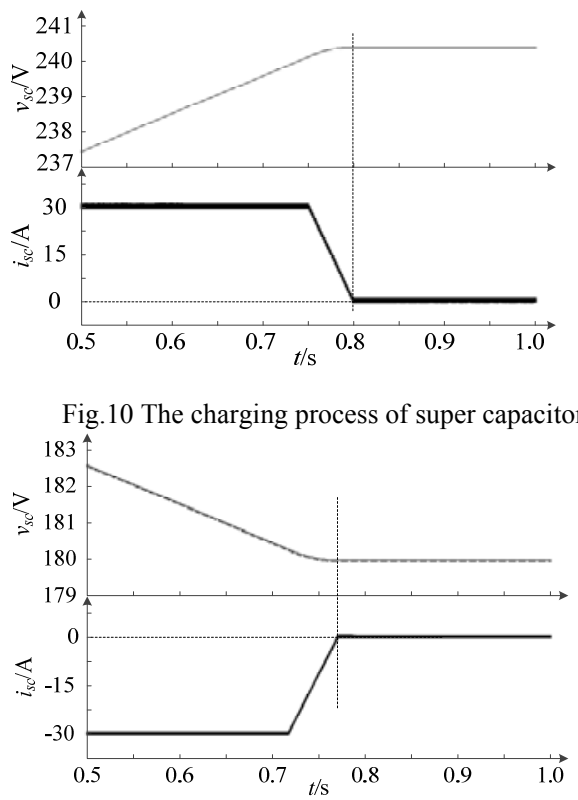

Fig.11 The discharging process of super capacitor

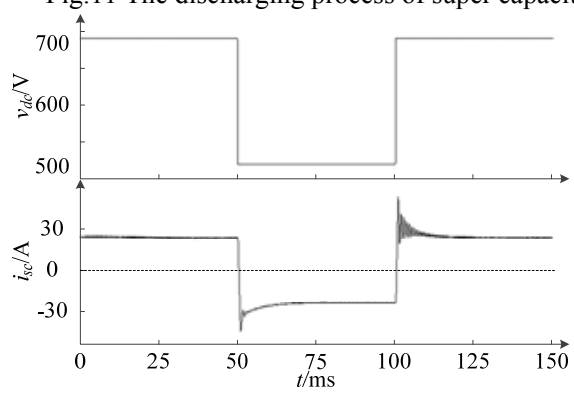

Fig.12 Charging and discharging switching of super capacitor

When the DC bus voltage is changed, the working mode of the bidirectional converter is switched, and the simulation result is shown in Figure 12. It can be seen from Figure 12 that when the DC bus voltage is suddenly reduced, the converter can realize the switch between buck mode and boost mode fast.

\section{CONCLUSION}

In this paper, the control strategy of energy storage elevator with super capacitor based on non-isolated buckboost bidirectional DC converter is proposed aiming at the problem of interference of harmonic wave in energy feedback power grid method. The structure and the model of energy storage elevator with super capacitor are analyzed, and the charging and discharging control strategy of super capacitor is studied, and then the simulation model of super capacitor energy storage system is built up. The simulation results show that the proposed energy storage control strategy can achieve the regenerative energy recycling and reusing, is of great significance to the research on energy saving elevator.

\section{Acknowledgment}

This work was supported by the Province Public Welfare Technology Research Industry Project for Zhejiang under grand No. 2016C31115 and Huzhou public welfare Technology Application Research Project under grant No. 2015 GZ05.

\section{References}

[1] Phattanasak, M., Gavagsaz-Ghoachani, R., Martin, J.-P., NahidMobarakeh, B., Pierfederici, S., Davat, B.. "Control of a Hybrid Energy Source Comprising a Fuel Cell and Two Storage Devices Using Isolated Three-Port Bidirectional DC-DC Converters," IEEE Transactions on Industry Applications, Vol. 51, No.1, pp. 491-497, 2015.

[2] Shah, V.A., Mistry, D.J., Kundu, P., Maheshwari, R., "Single interrupt control and regenerative braking of PMBLDC motor for electric vehicles", International Journal of Vehicle Structures and Systems, Vol. 4, No. 1, pp. 10-17, 2012.

[3] Ozel, O., Shahzad, K., Ulukus, S.. "Optimal Energy Allocation for Energy Harvesting Transmitters With Hybrid Energy Storage and Processing Cost," IEEE Transactions on Signal Processing covers novel theory, Vol. 62, No. 12, pp. 3232-3245, 2014.

[4] Jinping He, Chengxiong Mao, Jiming Lu, and Jiawei Yang. "Design and Implementation of an Energy FeedbackDigital Device Used in Elevator[J]. IEEE Transactions on Industrial Electronics," Vol. 58, No. 10, pp. 4636-4642, 2011.

[5] Estanis Oyarbide, Ivan Elizondo, Abelardo Martínez-Iturbe, Carlos Bernal, Javier Irisarri "Ultracapacitor-based plug \& play energyrecovery system for elevator retrofit", 21th Annual Conference of the IEEE Industrial Electronics, (ISIE'2011), Berkeley, California, USA, 7-10 Jun 2011, pp. 462-467.

[6] Ragavan, S.V., Kumar, J.M., Ponnambalam, S.G., "Design of a mechatronic drive train with Regenerative Braking", Applied Mechanics and Materials, Vol. 110-116, Oct. 2011, pp. 5111-5117.

[7] Grossard, M., Kachroudi, S., Abroug, N., "An optimal energy-based approach for driving guidance of full Electric Vehicles", 2012 IEEE International Symposium on Industrial Electronics (ISIE), Hangzhou, China, 28-31 May 2012, art. No. 6237348, pp. 1708-1713.

[8] Ming-Ji Yang, Hong-Lin Jhou, Bin-Yen Ma and Kuo-Kai Shyu, “A Cost-Effective Method of Electric Brake with Energy-Regeneration for Electric Vehicles", IEEE Transactions on Industrial Electronics, Vol. 56, No. 6, June 2009, pp. 2203-2212

[9] Christidis G.C., Karatzaferis I.Ch., Sautreuil M., Tatakis E.C., Papanikolaou N.P., "Modeling and Analysis of an Innovative Waste Heat Recovery System for Helicopters," 15th European Conference on Power Electronics and Applications (EPE'2013), Lille (France), 3-5 September, 2013, paper on CD, No 0715.

[10] Christidis G.C., Karatzaferis I.Ch., Perpinias I.I., Sautreuil M., Bezes G., Papanikolaou N.P., Loupis M., Spanoudakis I. and Tatakis E.C., "Innovative Waste Heat Recovery Systems in Rotorcrafts", International Conference on Electrical Systems for Aircraft, Railway and Ship Propulsion (ESARS'12), October 16-18, 2012, Bologna (Italy), ID SS10005, paper on CD.

[11] CIBSE, "Guide D Transportation Systems in Buildings," 2005.

[12] J. Nipkow, "Electricity Consumption and Efficiency Potentials of Lifts," Report of Swiss Agency for Efficient Energy Use (SAFE), HTW Chur University of Applied Sciences, Zurich, 2005. 
[13] Boonyang Plangklang, Sittichai Kantawong, Sirichai Dangeam. "Elevator Energy Regenerative Unit (EERU) for Energy Saving in a Permanent Magnet Motor Elevator System," 17th International Conference on Electrical Machines and Systems (ICEMS), 2014, pp. 2120-2124. Hangzhou, China
[14] Lei, Z., Yugong, L., Diange, Y., Keqiang, L., Xiaomin, L., "A novel brake control strategy for electric vehicles based on slip trial method," IEEE International Conference on Vehicular Electronics and SafetyICVES, Beiging, China, 13-15 Dec 2007, art. no. 4456364. 